Revista Monografias Ambientais

Santa Maria, Edição Especial Curso de Especialização em Educação

Ambiental. 2015. p.66-70

Revista do Centro de Ciências Naturais e Exatas - UFSM

\title{
Bioconstruções: Superadobe como vetor da sustentabilidade
}

\author{
Bioconstruction: Superadobe as Sustainability Vector
}

\author{
Josiane Pillar Hinning ${ }^{1}$, Denise Saad ${ }^{2}$ \\ ${ }^{1}$ Arquiteta e Urbanista, Especialista em Ed. Ambiental, Mestra em Patrimônio Cultural, \\ Docente Técnico em Edificações do Instituto Federal Farroupilha, Campus Panambi, RS, Brasil. \\ ${ }^{2}$ Engenheira Civil, Doutora em Engenharia Civil, Professora do Programa de Pós-Graduação \\ Profissionalizante em Patrimônio Cultural. UFSM. Santa Maria, RS, Brasil.
}

\section{Resumo}

O presente trabalho apresenta a pesquisa sobre a técnica construtiva do Superadobe, realizada no Curso Técnico em Edificações, no Instituto Federal Farroupilha, Campus Panambi. A atividade foi desenvolvida durante a Disciplina de Conforto das Edificações. O método de bioconstrução pesquisado foi o Superadobe. A técnica construtiva foi idealizada pelo arquiteto iraniano Nader Khalili e consiste em construir com o solo proveniente do próprio local, bem como com auxilio de demais materiais como areia, embalagens plásticas, entre outros. A pesquisa realizada pretende subsidiar a elaboração de um projeto de uma tipologia residencial, onde será incorporada a representação da técnica construtiva. Também foi desenvolvido estudo sobre os conceitos da Permacultura, que aliam diversos saberes relacionados às boas práticas, que possibilitam a criação de ambientes sustentáveis. Os aspectos de conforto ambiental nas construções com o superadobe também foram pesquisados. Através desta atividade, foi possivel ampliar as percepções acerca das possibilidades de materiais e técnicas com menor impacto ambiental, vindo ao encontro dos conceitos de sustentabilidade e da Educação Ambiental.

Palavras-chave: Bioconstruções, superadobe, permacultura.

\begin{abstract}
This paper presents the research on the construction technique of Superadobe held in the Technical Course in Building, at the Federal Institute Farroupilha, Campus Panambi. The activity was developed during Discipline Comfort in Buildings. The bioconstruction method studied was the Superadobe. The construction technique was designed by the Iranian architect Nader Khalili, and consists of building with the soil from the spot, and with the help of other materials such as sand, plastic packaging among others. The research aims to support the development of a project of a residential typology, where the representation of the construction technique will be incorporated. It was also carried out a study on the concepts of permaculture, which combine different knowledge related to best practices that enable the creation of sustainable environments. Aspects of environmental comfort in buildings with superadobe were also searched. Through this activity, it was possible to enlarge the perceptions about the possibilities of materials and techniques with lower environmental impact, coming to meet the concepts of sustainability and environmental education.
\end{abstract}




\section{Introdução}

As construções com terra são muito antigas, várias civilizações desenvolveram técnicas diferenciadas acerca desta tecnologia sustentável. Os povos que mais utilizaram a técnica são os povos da Mesopotâmia e do antigo Egito. O presente trabalho apresenta a pesquisa realizada no Curso Técnico em Edificações, na modalidade Subsequente, no Instituto Federal Farroupilha, Campus Panambi/RS. A atividade foi desenvolvida durante a Disciplina de Conforto das Edificações, contando ainda com pesquisas realizadas na Disciplina de Materiais e Técnicas Construtivas. Nesta atividade, foi pesquisado o método de construção através do Superadobe, que é uma alternativa de construção que alia melhorias em prol do meio ambiente e confere conforto ambiental para as edificações. A pesquisa destacou o autor da técnica, o arquiteto iraniano, Nader Khalili, fundador do Instituto Calearth, Centro de referência que fica na Califórnia, EUA. A técnica foi premiada em um Concurso promovido pela Nasa.

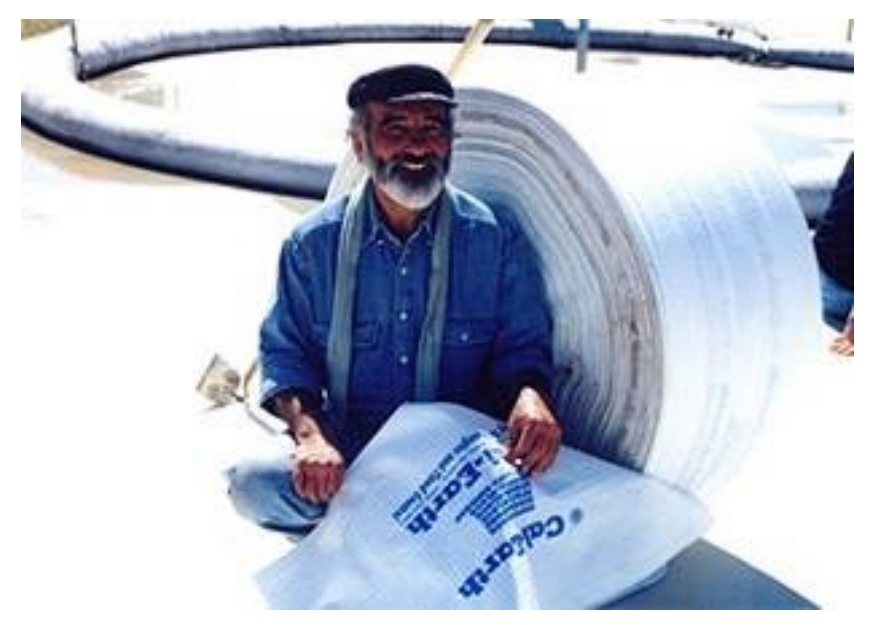

Figura 1: Nader Khalili. (1936-2008)

Fonte: www.calearth.org

\section{Objetivos}

Os objetivos principais da atividade foram a pesquisa sobre a técnica construtiva e os materiais empregados. O Superadobe consiste em construir com o solo proveniente do próprio local, bem como com auxílio de demais materiais. A pesquisa realizada pretende subsidiar a futura elaboração de um projeto de uma tipologia residencial e uma maquete envolvendo a representação da técnica construtiva, para a execução de um protótipo em escala real. Foram estudados ainda os conceitos da Permacultura, que aliam diversos saberes relacionados às boas práticas. Também foram pesquisadas as obras do arquiteto alemão Gernot Minke. O Manual de Curso sobre Bioconstruções do Ministério do Meio Ambiente, elaborado pela arquiteta Cecília Prompt no ano de 2008, também foi uma importante fonte de pesquisa sobre a técnica. 


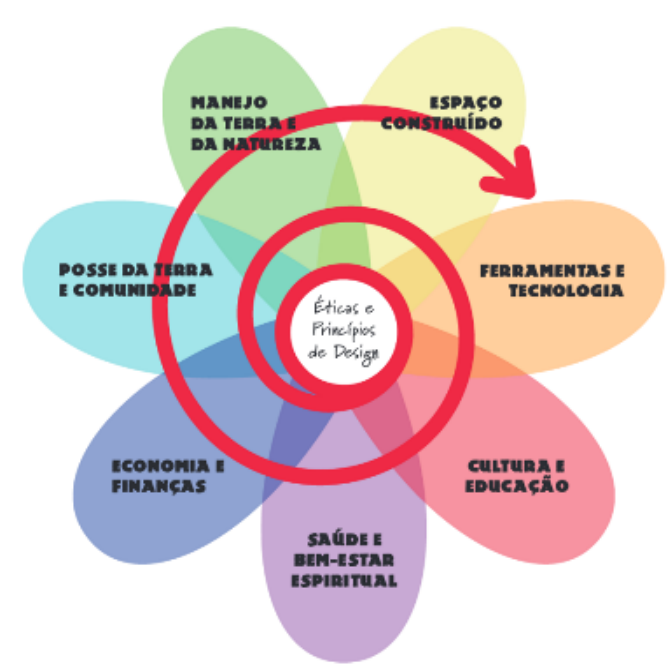

Figura 2: Flor da Permacultura

Fonte: http://www.permacultureprinciples.com/pt/

A figura 03 apresenta os materiais e o passo a passo da técnica construtiva, descritos no Manual do Ministério do Meio Ambiente. Os materiais para a execução são sacos de ráfia ou embalagens préfabricadas para a finalidade, arame farpado e terra. As ferramentas são tubos de $25 \mathrm{~cm}$ de diâmetro, balde sem fundo, pilões, martelos de borracha, enxada e pá.

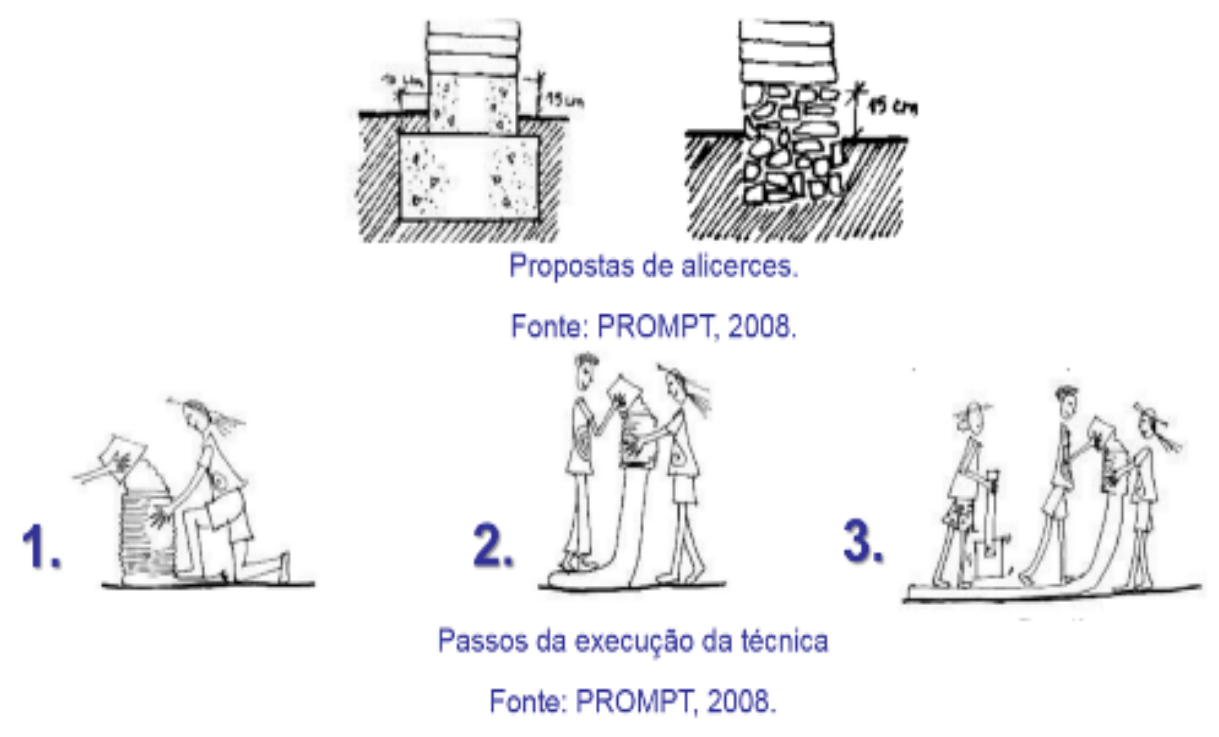

Figura 3: Representação da técnica construtiva do Superadobe.

Fonte: www.mma.gov.br/estruturas/sedr_proecotur/_publicacao/140_publicacao15012009110921.pdf

\section{Metodologia}

Este trabalho foi desenvolvido inicialmente através de revisão bibliográfica, desenvolvida pela turma acerca da temática bioconstruções. Após foi apresentado o Documentário "El barro, Las manos, La casa". 2013, do construtor argentino Jorge Belanko, que apresenta um testemunho de que é possível construir através de práticas menos impactantes ao meio ambiente, através de técnicas que utilizam como principal matéria prima o solo do local. 


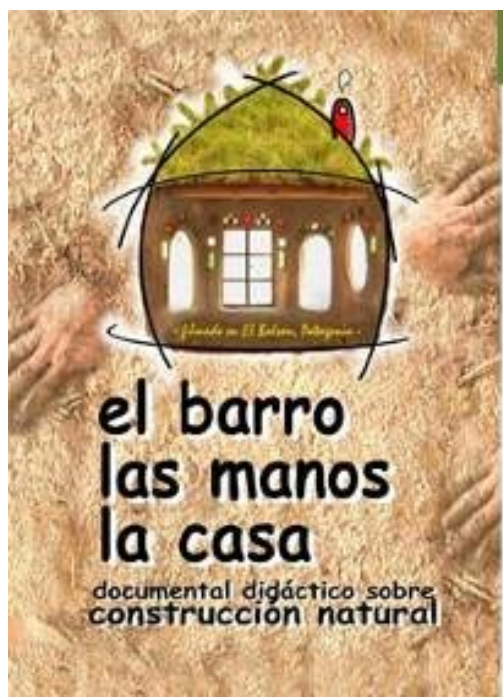

PROYLCCION DE LA PELICULA,

RESENIACION DEJORGE BELANKO

\section{Viernes 25 de Julio, 18 hs}

\section{Mitre 434}

Sede del Colegio de Arquitectos de San Luis
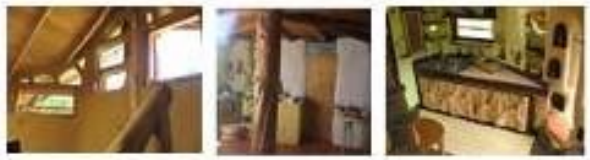

Entrada libre y gratuita.

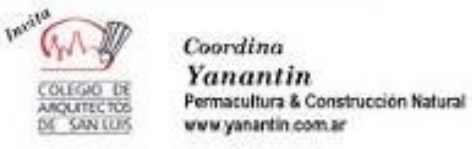

Figura 4: Documentário El barro, las manos, la casa. Jorge Belanko.

Fonte: http://www.casatierra.org.ar/

\section{Referencial teórico}

Foram pesquisados diversos autores, destacamos o referencial que segue:

Segundo, PROMPT (2008), o Superadobe é uma técnica de bioconstrução que utiliza embalagens com terra comprimida para fazer paredes e coberturas. As figuras 05 e 06 apresentam o esquema da execução das aberturas.
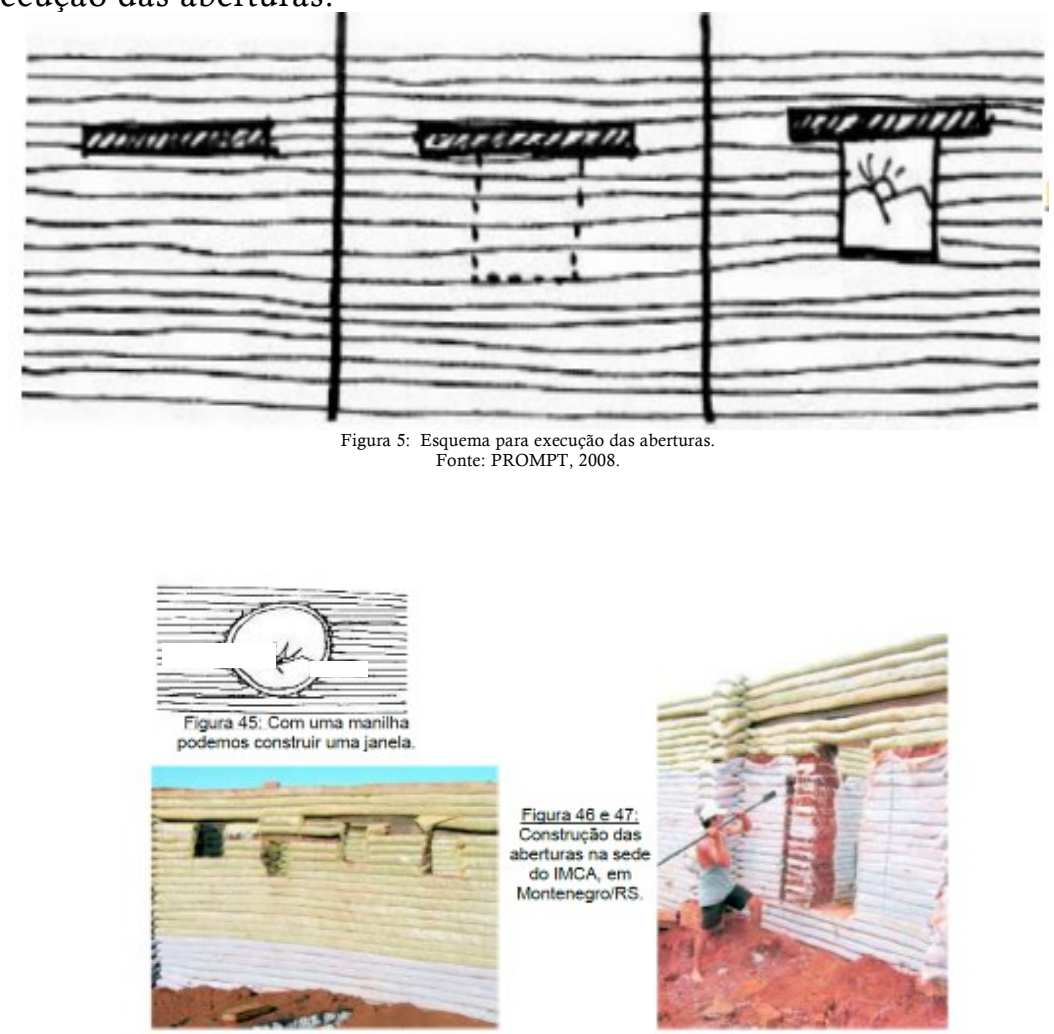
O Superadobe pode ser categorizado como uma ecotécnica construtiva, pois atende a uma série de quesitos que efetivamente contribuem para um ambiente construído equilibrado e sustentável. Conforme LENGEN, uma ecotécnica confere a casa é um ambiente agradável, com conforto térmico, bem ventilada, recebe a luz do sol, não tem umidade, tem bom isolamento acústico podemos dizer que em seu planejamento e construção foram consideradas as ecotécnicas.

O superadobe é uma ecotécnica que permite aliar a mesma forma de construir, da fundação ao telhado, mas também é possível executar outros tipos de coberturas, como o telhado verde por exemplo.

Conforme Dias (2010), o World Business Council for Sustainable Development - WBCSD (1996), apresenta os sete fatores que devem ser atingidos para que haja ecoeficiência: 1. Reduzir a intensidade de uso de materiais; 2. Diminuir a demanda de energia; 3. Reduzir a dispersão de substâncias tóxicas; 4. Incentivar a reciclagem dos materiais; 5. Maximizar o uso sustentável dos recursos renováveis; 6. Prolongar a vida útil dos produtos; 7. Incrementar a intensidade de serviços. Ao construir com Superadobe, todos os itens citados acima são potencializados.

\section{Resultados e discussão}

Através desta pesquisa foi possível provocar questionamentos acerca das variadas técnicas construtivas convencionais, comparando com os benefícios da utilização do Superadobe, que como foi visto é uma alternativa sustentável e ecoeficiente.

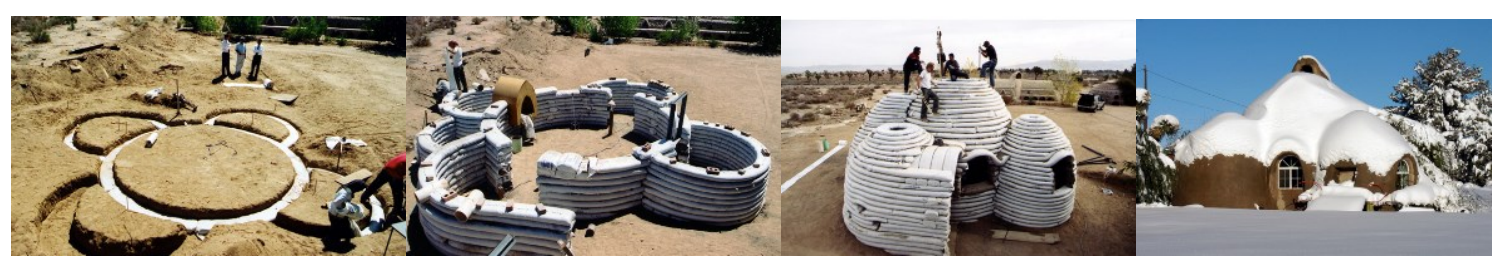

Figura 7: Registros da execução de uma edificação de Superadobe.

Fonte: www.calearth.org

\section{Conclusões}

Através desta atividade, foi possível ampliar as percepções acerca das possibilidades de materiais e técnicas com menor impacto ambiental, aliando conceitos de sustentabilidade e da educação ambiental. A técnica pesquisada é uma ótima alternativa relacionada ao conforto ambiental, pois as paredes apresentam uma dimensão maior que outras técnicas convencionais. A pesquisa aponta caminhos para a proposição de um futuro espaço educativo, é uma fase que irá subsidiar outras experiências práticas com o Superadobe.

\section{Referências}

ANAIS do III Congresso Internacional de Educação Ambiental. ISSN: 2236-1154. 2014. Disponível em CD.

BRASIL. Ministério do Meio Ambiente. Secretaria de Extrativismo e Desenvolvimento Rural Sustentável. Departamento de Desenvolvimento Rural Sustentável. Curso de Bioconstrução. Texto elaborado por: Cecília Prompt - Brasília: MMA, 2008. 64 p.

BRASIL. Lei n ${ }^{\circ}$ 9.795, de 27 de abril de 1999.

BELANKO, Jorge. Bioconstrução - O Barro, as mãos, a casa / E1 barro, Las manos, La casa. 2013.

CALEARTH. Disponível em: <http://calearth.org/>. Acesso em: set. 2014.

CASATIERRA. Disponível em: <http://www.casatierra.org.ar/act 2008-07-25.asp>. Acesso em: set. 2014. 
DIAS, Reinaldo. Gestão Ambiental: Responsabilidade social e sustentabilidade. São Paulo/SP. Atlas. 2010, p. 130-131.

LENGEN, Johan Van. Manual do arquiteto descalço. Editora Empório do Livro. São Paulo. $5^{\text {a }}$ Edição. 2014, pp. 536-537.

Ministério do Meio Ambiente. Disponível em:

http://www.mma.gov.br/estruturas/sedr_proecotur/_publicacao/140_publicacao15012009110921.pdf Acesso em: set. 2014

MINKE, Gernot. Manual de Construção em terra. 2001.

Permacultura Principles. Disponível em: http://www.permacultureprinciples.com/pt/. Acesso em: set. 2014.

PROMPT, Cecília. Curso de Bioconstrução. Ministério do Meio Ambiente. 2008.

Tibarose. Disponível em: http://www.tibarose.com/port/cursos.php. Acesso em: set. 2014. 